\title{
Transition of diesel spray to a supercritical state under engine conditions
}

International J of Engine Research 2016, Vol. 17(I) 108-119 (c) IMechE 2015

Reprints and permissions: sagepub.co.uk/journalsPermissions.nav DOI: $10.1177 / \mid 46808741560428$ jer.sagepub.com

๑SAGE

\author{
Michael Wensing', Thomas Vogel' and Gudrun Götz ${ }^{2}$
}

\begin{abstract}
Process operating conditions of modern internal combustion engines can exceed the thermodynamic critical point of an injected liquid fuel. This raises the question of whether the fuel, or at least some of its components, transition to a supercritical state, even in the presence of an ambient gas. Further investigation is required for a better understanding of heat and mass transfer during the process of fuel injection in diesel engines. This article investigates the phase behavior of fuels and their components under supercritical conditions or when injected into such. After a brief review of the current state of research on the topic, we present our study of the phase behavior of three single-component liquids (n-heptane, n-dodecane, n-hexadecane) and their binary mixtures under supercritical conditions in a nitrogen environment using equations of state. In first experiments, these liquids along with a diesel fuel were successfully transitioned to supercritical states by applying engine-relevant but steady state conditions inside a high-pressure, high-temperature constant volume chamber. No influence of the ambient nitrogen on the phase behavior of the examined fluids was found. For further investigation, multicomponent fuels were injected into the chamber in a transient injection process and at typical engine-relevant time scales using a production-type diesel injector. The fuel sprays were examined with Mie scattering, laser-induced fluorescence, and shadowgraphic imaging. The information obtained confirms the presence of a supercritical state and a transcritical phase change. Areas of high density with pronounced fluctuations were visible. The theoretical review in combination with the results obtained from the experiments indicate that fuel injected under the high-pressure and high-temperature conditions, that are present in modern diesel engines at higher loads, does not evaporate but rather shows transition to a supercritical state with a disappearing phase border, but without boiling or changing density.
\end{abstract}

\section{Keywords}

Supercritical condition, diesel, injection, critical point, transcritical process

Date received: II May 20I5; accepted: 13 August 2015

\section{Introduction}

Recent developments in diesel engines toward higher compression pressures lead to an increase in pressure and temperature near top dead center on fuel injection. Liquid fuel is injected into a gaseous $\mathrm{N}_{2} / \mathrm{O}_{2}$ environment exceeding the thermodynamic critical temperature $\mathrm{T}_{\mathrm{c}}$ and pressure $\mathrm{p}_{\mathrm{c}}$ of most common diesel fuel components. This leads to the assumption that the critical point of a multicomponent fuel would also be exceeded.

Fuel injection is traditionally understood as comprising atomization processes, subdivided into primary and secondary breakup and vaporization of the injected liquid. ${ }^{1}$ The following work shows that this model does not, however, apply in the case of fuel injection into modern diesel engine at a higher load.
A fluid exceeding its critical temperature and pressure, known as a supercritical fluid, has the characteristics both of a liquid and a gas. The densities of the liquid and gaseous phases become equal at the critical point. Despite the high density, the intermolecular

\footnotetext{
'Institute of Engineering Thermodynamics (LTT) and Erlangen Graduate School in Advanced Optical Technologies (SAOT), Friedrich-AlexanderUniversity of Erlangen-Nuremberg (FAU), Erlangen, Germany

${ }^{2}$ Intellectual Property IP-GÖTZ, Nuremberg, Germany
}

\section{Corresponding author:}

Michael Wensing, Institute of Engineering Thermodynamics (LTT) and Erlangen Graduate School in Advanced Optical Technologies (SAOT), Friedrich-Alexander-University of Erlangen-Nuremberg (FAU), Am Weichselgarten 8, 91058 Erlangen, Germany. Email: michael.wensing@fau.de 


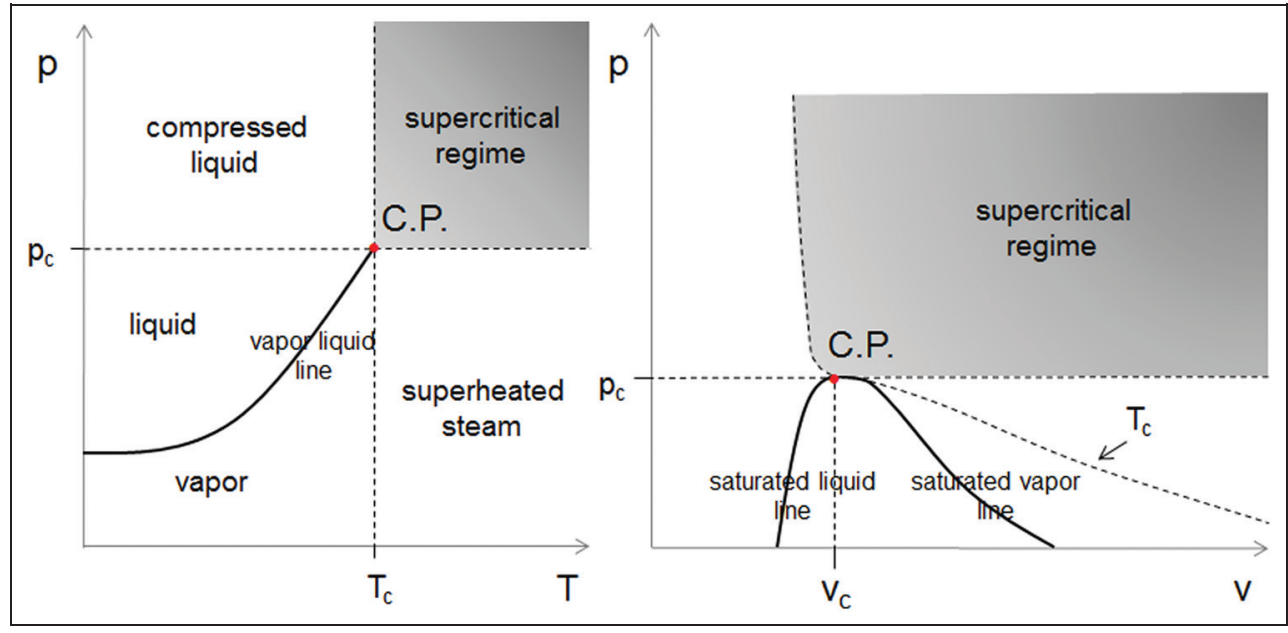

Figure I. Graphical representation of the supercritical regime.

forces are smaller than the kinetic forces, leading to a high diffusion coefficient, fast heat and mass transport, and a considerable decrease in surface tensions. As a result, phase boundaries do not exist; a supercritical fluid has only one phase (see Figure 1), for substances as well as for multicomponent mixtures. ${ }^{2,3}$ The supercritical regime is defined by the fluid's critical isotherm and isobar (dashed lines).

There is broad usage of the special properties of supercritical fluids in chemical engineering. ${ }^{4}$ For reactions, for example, supercritical fluids have the following advantages: The energy required to break the bonds between single molecules is low due to the small intermolecular forces. The high kinetic forces lead to the formation of clusters of different density ${ }^{5}$ near and above the critical point. Thus, mixing processes as well as heat and mass transfer are highly accelerated. A generally high density enables a high degree of interaction between different species. ${ }^{6}$

Regarding evaporation and combustion, important properties of supercritical fluids are the absence of enthalpy of vaporization and the low surface tensions. Therefore, the formation of phase boundaries and droplets is severely limited. Fuel injected into high-pressure/high-temperature conditions transitions from a compressed liquid to a supercritical fluid. As shown in Figure 1, it is not necessary to pass the two-phase region (saturated liquid and saturated vapor lines), and there is subsequently no requirement for additional energy for phase transition. An overview of research up until 1999 on the phase behavior of one and two component droplets and jets under elevated condition is given by Bellan. ${ }^{7}$

There is also considerable research on the role of supercritical fluids in combustion engine processes for liquid propellant rocket engines. ${ }^{8}$

\section{Overview of recent research}

In the context of a cooperation between the Air Force Research Laboratory (AFRL) and the German
Aerospace Center (DLR), an experimental study on liquid nitrogen $\left(\mathrm{lN}_{2}\right)$ injected into gaseous nitrogen $\left(\mathrm{gN}_{2}\right)$ at supercritical conditions was conducted by Chehroudi et al. ${ }^{9}$ In the study, liquid $\mathrm{N}_{2}\left(\mathrm{NN}_{2}\right)$ is injected into an atmosphere of gaseous $\mathrm{N}_{2}\left(\mathrm{gN}_{2}\right)$ at different reduced pressures. The initial temperature of the $1 \mathrm{~N}_{2}$ is beneath its critical temperature, whereas the chamber temperature strongly exceeds its critical value. At a reduced pressure of 0.91 , the structures of ligaments and droplets are visible. Spray clearly stands out from the environment. With increasing pressure, these structures start vanishing. A formation of Schlieren structures-zones with high-density fluctuations resulting in high diffraction of the background illumination - can be observed at the outer parts of the spray cone. At a reduced pressure of 2.71 , the injected liquid becomes indistinct in the surrounding atmosphere; a phase boundary in between different phases is no longer clearly defined.

These observations apply not only to liquid nitrogen; similar behavior is demonstrated for the injection of other liquid gases, such as oxygen, into gaseous environments in supercritical conditions. It is not certain that the results could be applied in an internal combustion engine (ICE), especially in high compression ratio diesel engines. The fuel injected in a diesel process consists of various hydrocarbons with a much higher molecular weight than the gases investigated here. In addition to the substantial difference in the molecular weights, there is also a substantial difference in the chemical structures between the injected fuels and the environmental gases. These factors influence the critical behavior of the injected fuel.

Recent research focusing on droplets under supercritical conditions has been conducted as part of the Collaborative Research Centre (SFB-TRR 75) funded by the German Research Foundation. ${ }^{10}$ Within this framework, a droplet generator has been developed by Weckenmann and colleagues, ${ }^{11,12}$ with the aim of studying droplets of the organic liquid acetone in a supercritical, pure nitrogen environment. 
An acetone droplet in a nitrogen environment at different conditions has been observed from subcritical to supercritical temperatures and pressures for fluids. With shadowgraphic imaging, it was found that a clear phase boundary is visible around the whole droplet in subcritical conditions. As condition parameters increase, the phase boundary vanishes steadily and structures with finite width density gradients start to appear on the droplet's upper side. Although these structures are similar to those observed by Chehroudi et al., ${ }^{9}$ there is still a visible droplet with a clearly defined phase boundary at its lower side, indicating the presence of liquid acetone. This behavior can be understood since the liquid acetone is injected at a subcritical temperature; the comparative droplet takes time to warm up. At a time where the phase boundary has already started to vanish in places, liquid fuel is still present in other locations.

A series of experiments on the injection of an organic liquid (n-dodecane) into a supercritical environment was conducted by Dahms et al. ${ }^{13}$ Images of injected n-dodecane were taken by a high-speed camera equipped with a long-distance microscope. In subcritical conditions, the formation of ligaments and droplets can be observed. At ambient conditions exceeding the critical point of n-dodecane, structures with sharp phase boundaries are no longer visible, indicating that the fluid transfers to a supercritical state after injection rather than vaporizing from liquid to gas. The injection experiments were coupled with mixture fraction predictions obtained from large eddy simulations. ${ }^{14,15}$ Recent studies also look at droplets injected into a supercritical environment. ${ }^{16,17}$

Research more closely related to automotive fuels (gasoline and diesel) and ICE conditions is presented by Anitescu et al. ${ }^{18}$ The authors demonstrated a transition to a supercritical state for a diesel/gasoline mixture ("dieseline") and also showed a change in fuel sprays (a widening of cone angles) when ambient conditions are increased to supercritical conditions.

Until now, most work has used single-component liquids. The following study focuses on practical experiments starting with single-component fluids and proceeding to binary mixtures and diesel fuel used in current engine-relevant conditions. The experimental part is subdivided into two sections: The first section verifies whether a multicomponent diesel fuel can transfer to supercritical state in high-pressure/high-temperature conditions. In the second section, the phase behavior of diesel fuels injected into a supercritical environment is observed using optical measurement techniques in conditions and at time scales typical of diesel engine applications.

\section{Theoretical estimation of vapor-liquid equilibrium}

In preparation for the experiments, the actual conditions of an internal combustion process were initially simplified by considering a single-liquid/single-gas system. Three organic liquids covering the boiling range of common fuels were selected: n-heptane, n-dodecane, and n-hexadecane. For better intra-comparability, all selected liquids are n-alkanes, with ascending chain length. A pure Nitrogen atmosphere was used to suppress combustion. To initially assess fluid phase behavior and to specify the conditions for the following experiments, the critical points of the single fluids as well as those of mixtures were calculated.

Due to the absence of reliable vapor-liquid equilibrium (VLE) data, the critical properties of the binary mixture were estimated using three equations of state (EOS): two cubic (Peng-Robinson, ${ }^{19}$ Soave-Redlich$\mathrm{Kwong}^{20}$ ) and one viral (Lee-Kesler-Plöcker ${ }^{21}$ ). These equations are well established for estimating physical properties and are suitable for the given conditions such as high pressures, organic liquids, and the presence of diatomic gases. ${ }^{2,22}$ After comparing the data resulting from all three equations, the Soave-Redlich-Kwong equation was chosen to evaluate the VLE data for mixtures of two alkanes and the Lee-Kesler-Plöcker equation for mixtures containing nitrogen.

Of particular interest is the influence of air on the phase behavior of the fuel during injection. Therefore, the simplified mixtures containing an n-alkane and nitrogen were evaluated using the Lee-Kesler-Plöcker EOS.

Figure 2 shows the estimated critical points of mixtures for the three binary systems containing nitrogen. The calculated points are in good accordance with the typical behavior of a mixture on the van Konynenburg type III curve. ${ }^{24}$ As the critical temperature decreases with higher concentration of nitrogen, the critical pressure increases strongly to a multiple of the pure hydrocarbon critical pressures and values, that is, higher than the pressures reached in ICEs. These data are only valid for homogeneous mixtures and mole fractions of $\mathrm{x}_{\mathrm{N} 2}=0.62-0.86$.

A better approach for multicomponent fuels can be seen in the following series of graphs depicting the VLE of binary hydrocarbon mixtures. Figure 3 shows typical graphs for a van Konynenburg type I binary mixture. ${ }^{24}$ The critical points of mixtures form a curve connecting the critical points of the pure substances. The critical mixing temperatures are in between the single-component critical temperatures; the pressure rises to a maximum and descends again. The mixing of substances with similar chemical structures does not change the critical properties dramatically (compare Figure 2). All critical mixing temperatures and pressures are within conditions typically reached during a compression-ignition (CI) combustion process.

\section{Experimental section}

The experiments were conducted in two stages. First, the influence of a diatomic, gaseous atmosphere on the 


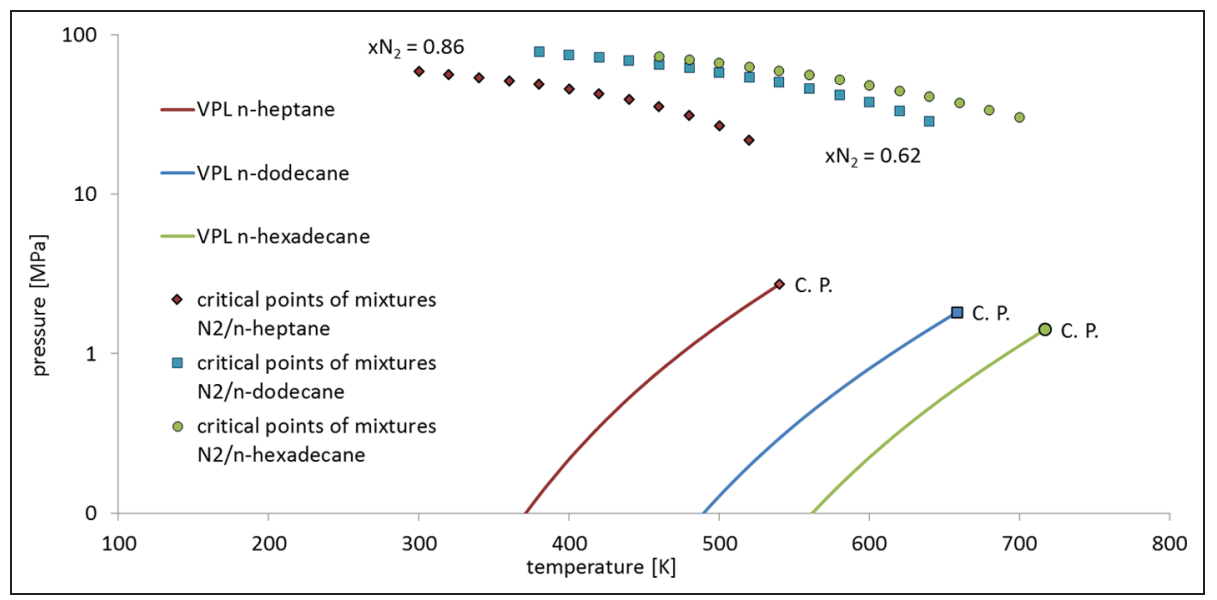

Figure 2. VLE of binary nitrogen/n-alkane mixtures including critical points and VPL of the pure substances and critical points of mixtures for several compositions $\left(x_{\mathrm{N} 2}=0.62-0.86\right)$; calculated using Aspen Properties ${ }^{23}$ with the Lee-Kesler-Plöcker EOS.

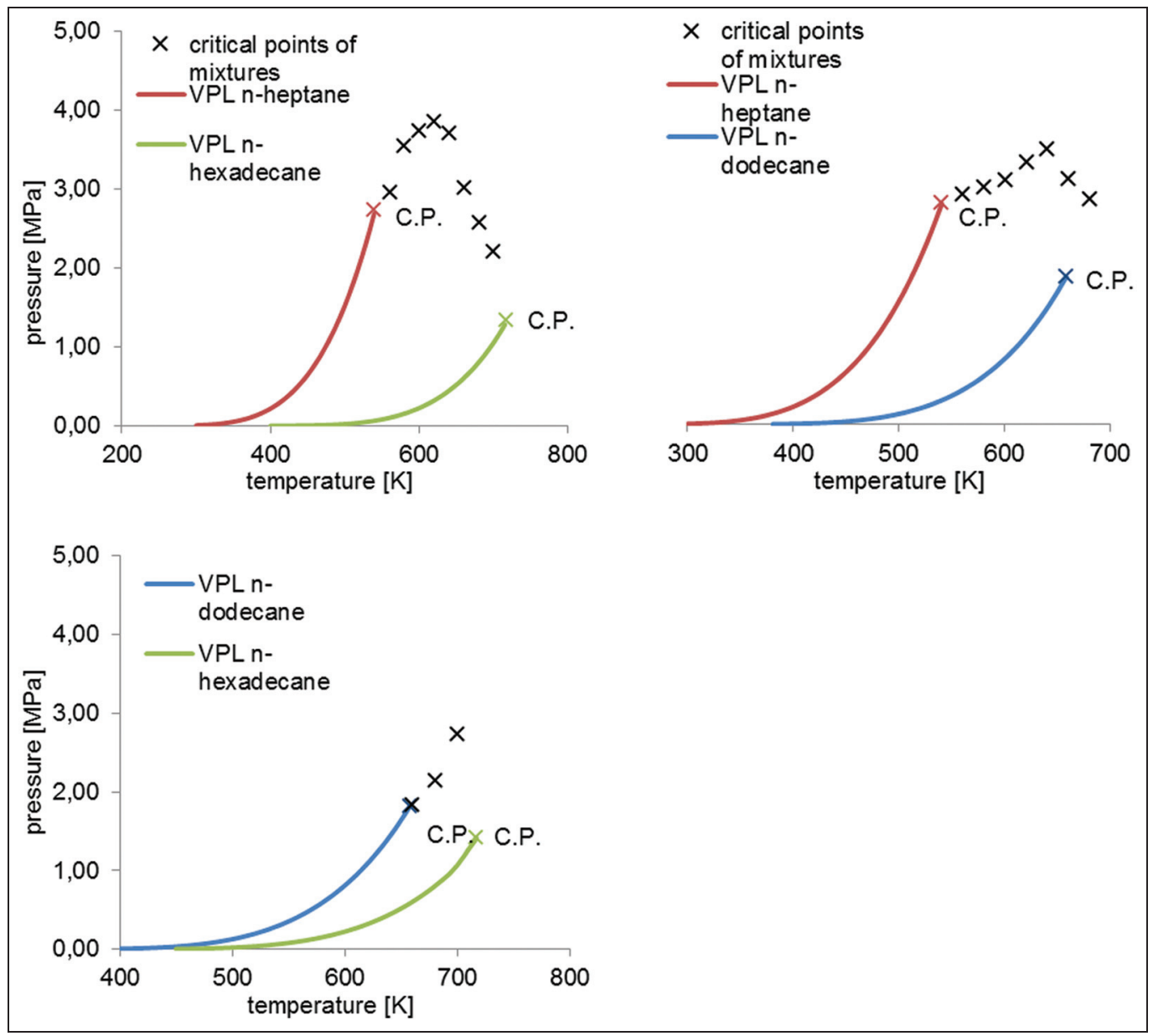

Figure 3. VLE of binary mixtures, including CP and VPL for the pure substances and critical points of mixtures (n-heptane/ $\mathrm{n}$-dodecane, $\mathrm{x}_{\mathrm{n} \text {-heptane }}=0.95-0.3 ; \mathrm{n}$-heptane/n-hexadecane, $\mathrm{x}_{\mathrm{n} \text {-heptane }}=0.9-0.1 ; \mathrm{n}$-dodecane $/ \mathrm{n}$-hexadecane, $\left.\mathrm{x}_{\mathrm{n} \text {-dodecane }}=0.99-0.90\right)$.

critical properties of an organic liquid was estimated for an ideal, homogeneous mixture. The objectives here were to verify this influence in engine-relevant conditions and to visualize a transition to a supercritical state for three single-component liquids. Therefore, the substances were positioned in an initially subcritical environment to which supercritical conditions were later applied. The observation obtained during the transition is valid both for binary mixtures and diesel fuels when estimating critical properties. Second, multicomponent fuels were injected directly into supercritical conditions. Different optical measurement methods, 


\begin{tabular}{|l|l|c|}
\hline gas pressure & $30 \mathrm{kPa}$ to $10 \mathrm{MPa}$ \\
\hline maximum temperature & $1000 \mathrm{~K}$ \\
\hline Inner vessel volume & 10 liters \\
\hline maximum scavenging flow rate & $110 \mathrm{~m}^{3} \mathrm{~N} \cdot \mathrm{h}-1$ \\
\hline scavenging medium & $\mathrm{N}_{2}$, air or mixtures \\
\hline clearance of the optical accesses & $125 \mathrm{~mm}$ \\
\hline maximum fuel pressure & $250 \mathrm{MPa} / 28 \mathrm{MPa}$ \\
(diesel/gasoline)
\end{tabular}

Figure 4. High-pressure and high-temperature injection chamber OptiVeP.

such as Mie scattering, laser-induced fluorescence (LIF), and shadowgraphic imaging, were used to visualize the phase behavior of the injected fluids. Although the environmental gas in ICE processes is air, pure nitrogen was used instead to suppress ignition.

\section{Experimental setup}

All experimental work was conducted in the optically accessible high-pressure/high-temperature injection chamber "OptiVeP" (see Figure 4) at the FAU Institute of Engineering Thermodynamics. A detailed description of the test rig itself can be found in previous articles. $^{25,26}$

\section{Transition to supercritical state}

In the first experiments, the transition to supercritical state of small volumes of single-component liquids, their binary mixtures, and a multicomponent mixture, a multicomponent diesel fuel was investigated. Therefore, defined volumes of those fluids were poured into a volumetric flask, which was positioned on a platform inside the vessel. The opening of the flask was left open, hence temperature and pressure inside the chamber equal those inside the flask in stationary conditions; heat and mass transfer is possible. To record the fluid during the experiment, a video camera was installed in front of a window of the chamber and a grid was placed behind the flask on the opposite side of the chamber.

Figure 5 shows the setup used in the first series of experiments. A $25-\mathrm{mL}$ volumetric flask filled with the substance under investigation was positioned on the insulation platform. $\mathrm{T}_{1}$ and $\mathrm{T}_{2}$ refer to two thermocouples additionally installed at the upper and lower ends of the flask neck to enable temperature measurement in the immediate vicinity. The resulting temperatures comprise the averaged data from both thermocouples. The red arrow indicates the phase boundary between liquid and surrounding gas, which was located below

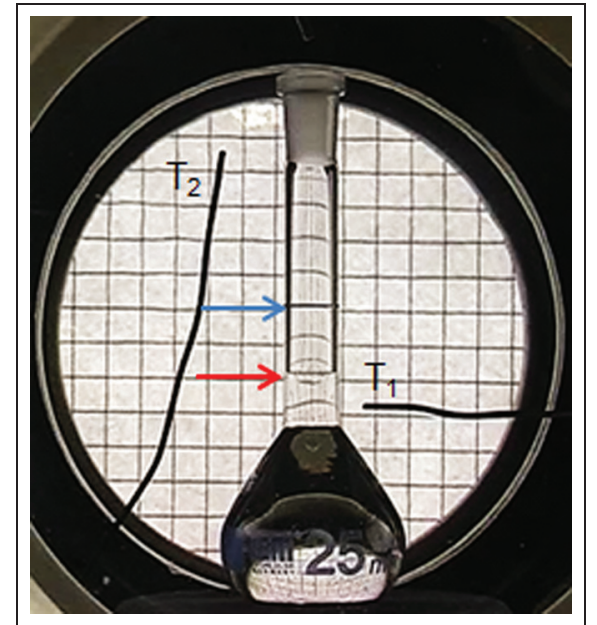

Figure 5. First-stage experimental setup inside the "OptiVep" constant volume vessel, including the positions of two thermocouples.

the flask calibration mark (blue arrow). Attention must be paid in the following images not to mistake this mark for the phase boundary. The mesh pattern was installed to obtain optical information on fluctuations of the refraction index resulting from changes in density. The experimental cycle to obtain one measurement point involves the following steps:

- Application of a constant pressure corresponding to the critical pressure of the liquid inside the chamber;

- Heating of the chamber up to an initial temperature $\mathrm{T}_{1}<\mathrm{T}_{\mathrm{c}}$

- Start of the recording process;

- Increasing the chamber temperature to a maximum temperature $\mathrm{T}_{2}>\mathrm{T}_{\mathrm{c}}$;

- Reducing the chamber temperature back to the initial temperature $\mathrm{T}_{1}<\mathrm{T}_{\mathrm{c}}$;

- Halting the recording process.

This experimental cycle was performed for the single-component fuels, their binary mixtures, and for the multicomponent diesel fuel.

Single components. The first set of measurements comprises the observation of the three single-component liquids n-heptane, n-dodecane, and n-hexadecane at different constant chamber pressures. The critical data of these substances can be found in conventional sets of tables and can be read from Table 1. This allows the definition and adjustment of temperature and pressure conditions with reference to the liquids tested. In addition, the influence of the surrounding nitrogen atmosphere can be investigated easily. Table 2 shows the values $\left(\mathrm{p}_{1}-\mathrm{p}_{5}\right)$ for the reduced pressures $\mathrm{p}_{\mathrm{r}}$ applied during the measurements as well as the initial and maximum temperatures $\left(\mathrm{T}_{1}, \mathrm{~T}_{2}\right)$ absolutely and as reduced values. 
Table I. Critical data and molar mass of pure components. ${ }^{22}$.

\begin{tabular}{lllll}
\hline & n-Heptane & n-Dodecane & n-Hexadecane & Nitrogen \\
\hline $\mathrm{T}_{\mathrm{c}}(\mathrm{K})$ & 540.2 & 658.3 & 717 & 126.2 \\
$\mathrm{P}_{\mathrm{c}}(\mathrm{MPa})$ & 2.73 & 1.82 & 1.42 & 3.39 \\
$\mathrm{~V}_{\mathrm{c}}\left(\mathrm{kg} / \mathrm{m}^{3}\right)$ & 234 & 238 & 240 & 314 \\
$\mathrm{M}(\mathrm{g} / \mathrm{mol})$ & 100.21 & 170.34 & 226.45 & 28.01 \\
\hline
\end{tabular}

Table 2. Measurement points for single components.

\begin{tabular}{lllll}
\hline & Reduced value & n-Heptane & n-Dodecane & n-Hexadecane \\
\cline { 4 - 5 } & & Temperature $(\mathrm{K})$ & \\
\hline $\mathrm{T}_{1}$ & 0.90 & 486.18 & 592.47 & 504.00 \\
$\mathrm{~T}_{2}$ & 1.20 & 648.24 & 789.96 & 860.40 \\
\cline { 3 - 5 } & & Pressure $(\mathrm{MPa})$ & & 2.84 \\
\cline { 3 - 4 } & & 5.46 & 3.64 & 2.13 \\
$\mathrm{P}_{1}$ & 1.00 & 4.10 & 2.73 & 1.70 \\
$\mathrm{P}_{2}$ & 1.50 & 3.28 & 2.18 & 1.49 \\
$\mathrm{P}_{3}$ & 1.20 & 2.87 & 1.91 & 1.28 \\
$\mathrm{P}_{4}$ & 0.9 & 2.46 & 1.64 & \\
$\mathrm{P}_{5}$ & & & & \\
\hline
\end{tabular}

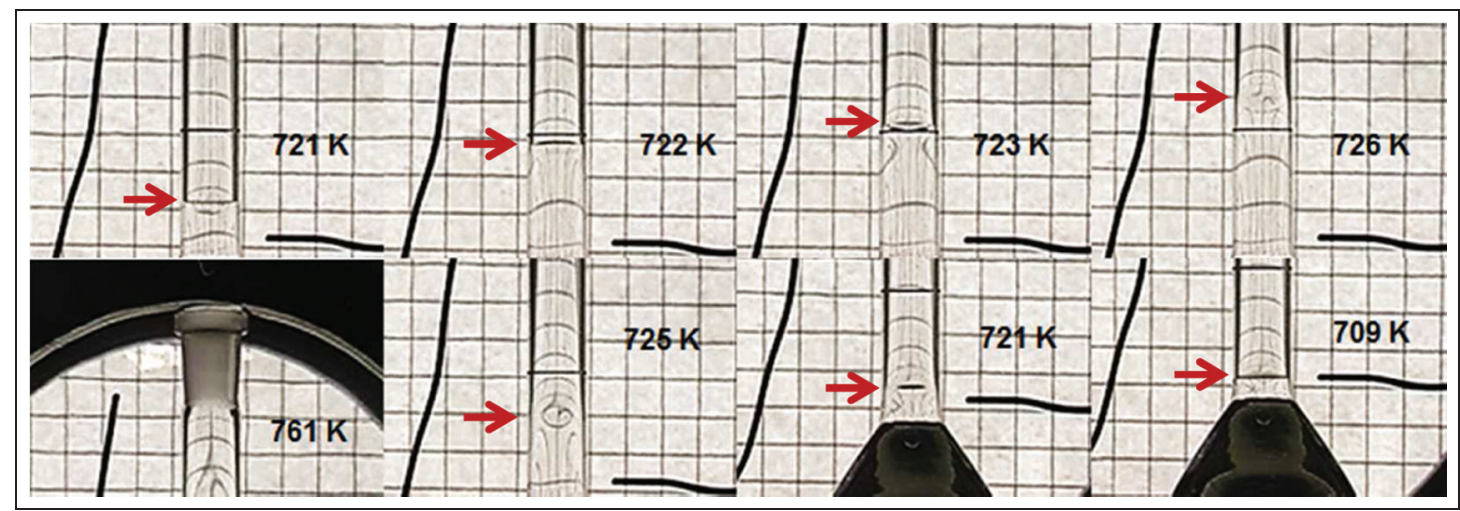

Figure 6. Transition to supercritical state of a single component in a high-pressure nitrogen environment ( $\mathrm{n}$-dodecane; $\mathrm{P}=2.73 \mathrm{MPa} ; \mathrm{Pr}_{\mathrm{r}}=1.5$ ); recording time $\approx 30 \mathrm{~min}$.

A typically observed transition to a supercritical state is, for instance, represented by n-dodecane in the following series of images in Figure 6 taken from the video recording. The pressure inside the chamber stays constant at $2.73 \mathrm{MPa}$, a reduced pressure of 1.5 . The temperatures range from approximately 592 to $790 \mathrm{~K}$ for the reduced temperatures of $\mathrm{T}_{1}=0.9$ and $\mathrm{T}_{2}=1.2$.

As chamber temperature increases, the phase boundary rises, separating the liquid from the gaseous $\mathrm{N}_{2}$ atmosphere (upper row images). In the image on the upper left side, the phase boundary is fully developed and located below the calibration mark. As the boundary rises, it starts to dissolve from the flask neck (second image from the left), exceeds the calibration mark, and finally vanishes completely (upper right image). An area of high-density fluctuations becomes visible instead. Further increase in temperature leads to a complete distribution of the fluid inside the flask. Part of the fluid exits the open end of the vessel (bottom-left image). When the temperature decreases, the entire process is reversed: the phase boundary becomes visible again and slowly descends inside the flask neck (bottom row of images). Although the duration of the experiment recorded was relatively long at $30 \mathrm{~min}$, not much fuel left the flask, indicating that the fuel density did not change significantly. Even though environmental nitrogen is present in excess, a transition to a supercritical state was obtained easily for all reduced pressures down to $\mathrm{p}_{\mathrm{r}}=1.2$.

Figure 7 presents the experimental critical temperatures for different pressures plotted as mean values. The phase boundary starts to dissipate (heating phase) and the first sign of a phase boundary appears (cooling phase). The error bar represents the minimum and the maximum temperature values for this particular experiment. The higher value is found at the transition from liquid to supercritical phase; the lower value from the reverse process. The differences are caused by the 
Table 3. Measuring points for binary mixtures.

\begin{tabular}{lllll}
\hline & Reduced value & n-Heptane/n-dodecane & n-Heptane/n-hexadecane & n-Dodecane/n-hexadecane \\
\cline { 3 - 5 } & & Temperature $(\mathrm{K})$ & & \\
\hline $\mathrm{T}_{1}$ & 0.90 & 486 & 486 & 592 \\
$\mathrm{~T}_{2}$ & 1.20 & 790 & 860 & 860.40 \\
\cline { 3 - 5 } & & Pressure $(\mathrm{MPa})$ & & 3.64 \\
\cline { 3 - 4 } & 2.00 & 5.46 & 5.46 & 2.73 \\
$\mathrm{P}_{1}$ & 1.50 & 4.10 & 4.10 & 2.18 \\
$\mathrm{P}_{2}$ & 1.20 & 3.28 & 3.28 & 1.49 \\
$\mathrm{P}_{3}$ & 1.05 & 2.87 & 1.91 & 1.28 \\
$\mathrm{P}_{4}$ & 0.9 & 2.46 & 1.64 & \\
$\mathrm{P}_{5}$ & & & & \\
\hline
\end{tabular}

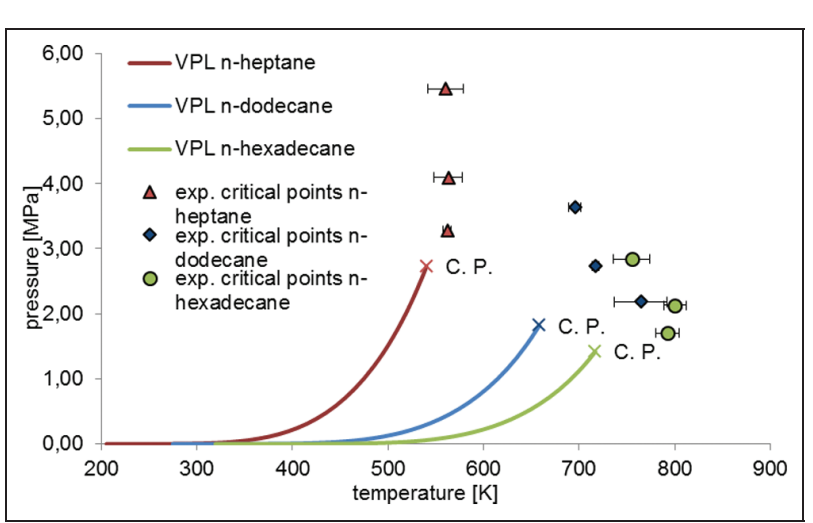

Figure 7. Experimental results for the three single components (n-heptane, n-dodecane, n-hexadecane).

delayed heat transfer from the ambient gas via the flask into the liquid.

All critical transition temperatures are higher than the single-component critical temperatures. This is mainly due to the delayed heat transfer from the chamber temperature into the fluid inside the flask. A direct measurement of the fluid temperature inside the flask was not taken to avoid disturbing the phase transition behavior by a thermocouple in the flask penetrating the phase boundary. Heat transfer is mainly dependent on the ambient conditions. At a higher gas temperature, the delay in the transcritical process is increased. At a higher gas pressure, the delay in heat transfer is shortened. The temperature delta between critical temperature and measured gas temperature at the critical transition also increases for the substances with a higher critical temperature, such as n-hexadecane. For $\mathrm{n}$-hexadecane, at the reduced pressure of 1.2 , the temperature delta is $\sim 80 \mathrm{~K}$. For n-heptane, the temperature difference is $\sim 30 \mathrm{~K}$. The increase in the critical mixture pressure for a homogeneous mixture containing an n-alkane and nitrogen is shown in Figure 2. Since a supercritical state can be achieved for all reduced pressures from 1.2 on, the influence of nitrogen can be disregarded. For n-heptane, the lowest calculated mole fraction of $0.62 \mathrm{~N}_{2}$ predicts a critical pressure of $30 \mathrm{MPa}$, which is approximately 10 times the critical pressure of pure $n$-heptane.

The transition from liquid to a supercritical state is visualized by the disappearance of the phase boundary. No other phase-changing process would result in this phenomenon. As previously mentioned, the surface tension of a supercritical fluid is very low. Thus, a phase boundary cannot exist between a supercritical fluid and the surrounding environment. In addition, two main differences can be seen when comparing evaporation monitored between subcritical measurement point $p_{5}$ and supercritical measurement point $\mathrm{p}_{4}$. Before the liquid evaporates, developing bubbles could clearly be seen indicating boiling. In contrast to the transition to the critical state, where the liquid volume first expands, a strong reduction in the liquid volume can be observed at subcritical conditions, while the phase boundary remains throughout the experiment. Compared to this loss of substance, which occurs during evaporation, the decrease in substance after transitions to a supercritical state and back in this experiment is minor due to the constant density of the supercritical fluid compared to a phase change from liquid phase to gas phase. It can be confusing that in this case, less mass transport is found for the transcritical phase change. This is because of the special geometry used in the experiment. In case of the transcritical phase change, the cross section for the mass transfer is limited by the flask. In case of the subcritical phase change, a strong volume expansion forces the evaporating fluid to leave the flask.

Multicomponents. The following section presents experiments with three binary mixtures each consisting of two of the three pure substances, with an initial composition of $50 \% \mathrm{~m} / \mathrm{m}$ of each component (Table 3). Since fluid composition in the course of the experimental cycle was not determined, it is unknown whether this composition changed due to the effects of separation, for example. The measurement points were selected according to the critical data of the pure substances.

Figure 8 plots the results of the n-heptane/ n-hexadecane mixture in comparison to the results 
taken from the single components as well as to the estimated VLE data.

The experimentally obtained critical mixing temperatures are positioned between the single-component critical temperatures. This is in good agreement with the critical mixture temperatures estimated using the EOS. All critical mixing temperatures and pressures found in experiments with one and two component liquids inside a nitrogen atmosphere are within the conditions achievable in realistic ICE processes.

After a successful experimental series for binary mixtures, the final step was the investigation of a multicomponent diesel fuel. Here, a gas-to-liquid (GtL) diesel was chosen. This fuel is produced by Fischer-Tropsch synthesis and, therefore, consists mainly of n-alkanes from the middle distillates group and is free from sulfur, aromatics, and additives. In contrast to common diesel fuels, it is transparent and colorless, which facilitates investigations by means of optical measurements. Although the GtL diesel differs from standard diesel fuel, it is compliant with EN $590^{27}$ except in density.

Critical mixing data for the fuel investigated are unknown but should be within the limits of the "OptiVep" test stand according to previous experiments. Therefore, the chamber pressure was set to a high value, $\mathrm{p}=8.0 \mathrm{MPa}$, and the temperature region ranged from approximately 643 to $873 \mathrm{~K}$. The following row of images in Figure 9 illustrates the fuel phase behavior during the experiment.

Similar to the preceding experiments, the liquid volume starts to expand as the temperature rises. The phase boundary, clearly visible in the far-left image,

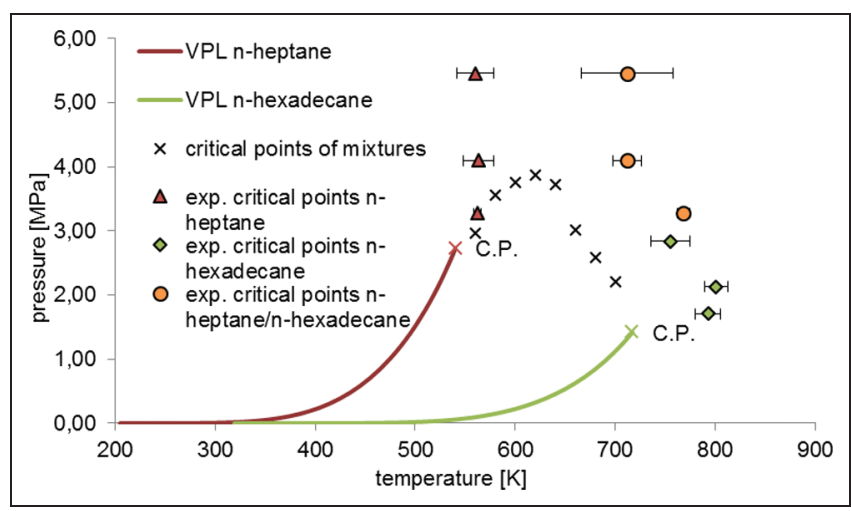

Figure 8. Experimental results for two single components (n-heptane, $n$-hexadecane) and their binary mixture. diminishes from the outer to the inner diameter at temperatures around $750 \mathrm{~K}$. This process is constant as temperatures climb and finishes at about $850 \mathrm{~K}$. In contrast to both prior experimental series, the transition to a supercritical state covers a much broader temperature range. This is due to the larger diameter of the phase boundary, which leads to delayed heat transfer into the liquid. Due to the high temperature in conjunction with long molecule chains and a small fraction of remaining oxygen in the ambient gas, a cracking process takes place after the fluid has reached its critical state. Therefore, the composition of the mixture is changed as it returns to its liquid state. This observation is in accordance with the results of the investigation by Lin and Tavlarides. $^{28}$ Thus, data collected during the cooling period could not be taken into account for the estimation of the critical temperature of the fluid.

The diagram in Figure 10 shows the critical points of n-alkanes from n-undecane to n-octadecane found in a typical GtL diesel fuel. Thermophysical properties of higher alkanes can differ in the literature and have therefore not been included in this diagram, although molecules with up to 22 carbon atoms can be found in diesel fuel. Gas pressure was set at $8 \mathrm{MPa}$, which is a typical value found in diesel engine cycles. Elevated critical pressures are also expected for mixtures of alkanes (see Figure 8). The temperature range at which the fuel transitions to a supercritical state is plotted, as well. This range is much higher than for the singlecomponent critical temperatures, which is mainly due to the heat transfer through the flask into the liquid.

\section{Injection into a supercritical environment}

The first part of the experiment showed that an actual diesel fuel can transfer to critical state in enginerelevant conditions. However, the influence of a surrounding gaseous atmosphere such as nitrogen is negligible if it is present in excess. Considering these results from the second part of the experiment, the fuel is directly injected into supercritical conditions. This injection process is highly transient, and therefore, the models used to calculate the critical conditions and the experiments in steady state can only give hints where the phase change behavior may change from evaporation to transcritical phase change. Furthermore, the contact of the fuel atomized to small drops $\left(\mathrm{d}_{10}<\right.$ $10 \mu \mathrm{m})$ and injected with high velocity to the surrounding gas is far more intense, and consequently, an effect

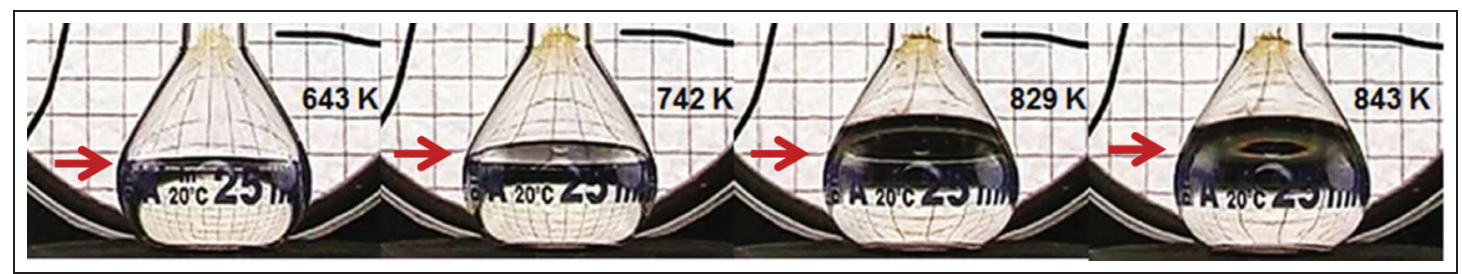

Figure 9. Transition to a supercritical state of a GtL diesel fuel $(P=8.0 \mathrm{MPa} ; \mathrm{T} \approx 643 \mathrm{~K}-873 \mathrm{~K})$; recording time $\approx \mathrm{I}$. 


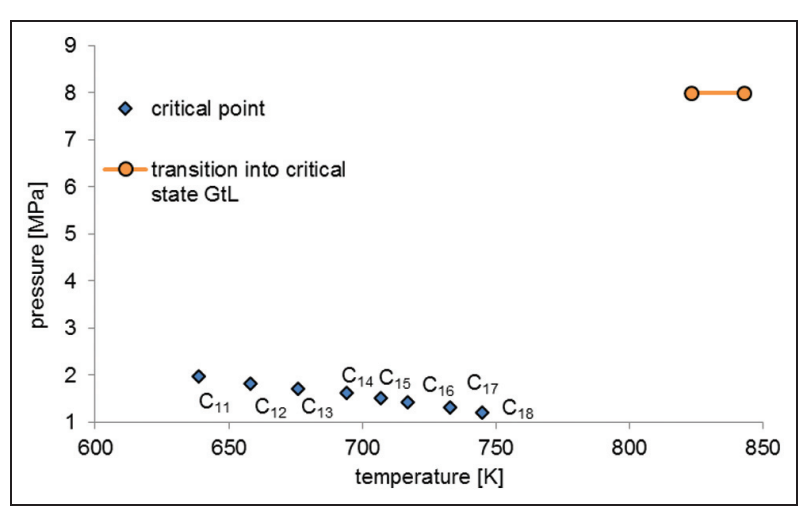

Figure 10. Experimental result for the GtL diesel fuel.

of the ambient gas on the phase change behavior may take place. Therefore, the focus is on obtaining information on the phase change behavior as the fuel is injected in the form of a diesel spray typical of automotive applications. The question is whether a phase boundary still exists between the droplets and the nitrogen environment. The most important parameter in this experiment is the pressure: if a subcritical pressure is applied, we expect an evaporation process from liquid to gas with lower density in the gas phase; if a supercritical pressure is applied, we expect a disappearing phase border and no density change when temperature is raised. Therefore, in all experiments, the pressure was kept constant while the temperature was changed to cause a phase change. In the injection experiment, the temperature change takes place by injecting a fuel with relatively low temperature into a hot gas. The heat transfer from the ambient gas heats the fuel rapidly to a high temperature so that liquid fuel is no longer visible.

The outer structures of the spray are also of interest. The spray cones are analyzed using optical measurement techniques: shadowgraphic imaging, LIF, and Mie scattering. Mie scattering as a surface scattering process is taken to identify the presence of surface boundaries and is expected to show clearly where liquid fuel is present. The situation for the LIF technique is not so clear since we to the best of our knowledge do not know an investigation about fluorescence intensity changes (maybe due to different quenching) in supercritical conditions. However, the LIF signal is based on the number of excited molecules and works in liquid and gas phases, and one can assume to get higher signal intensities from denser spray regions in supercritical conditions, too. Also for the shadowgraphic imaging, the situation is not simple since shadows are not only caused by surface scattering (inversed Mie imaging) but also by absorption of light and refraction of light due to gradients in the refractive index. Overall, the aim therefore is not to more or less quantify at what condition a transcritical phase change takes place but to qualitatively show whether fuel injected under the high conditions present in modern diesel engines at high load evaporates with a density change or loses its phase

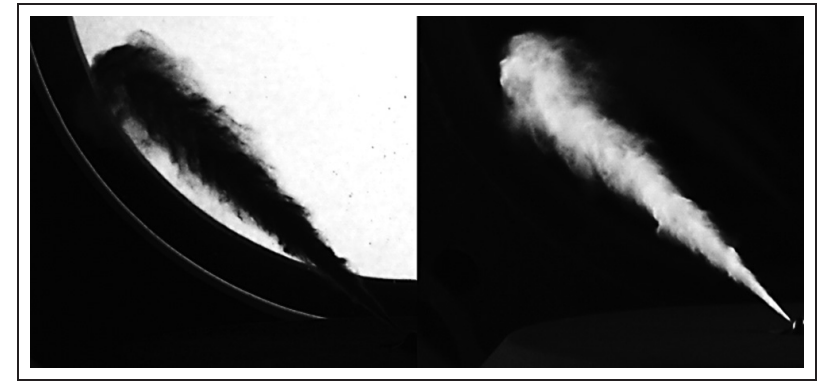

Figure I I. Injection of a GtL fuel ( $P_{\text {inj. }}=80 \mathrm{MPa} ; \mathrm{T}_{\text {inj. }}=323 \mathrm{~K}$; $\left.t_{v s O I}=1000 \mu s\right)$ into a subcritical environment $\left(\mathrm{Pg}_{\mathrm{g}}=\mathrm{I} \mathrm{MPa}\right.$; $\left.\mathrm{T}_{\mathrm{g}}=473 \mathrm{~K}\right)$.

border without density change. Therefore, different measurement techniques have been used.

Comparison of shadowgraphic imaging/Mie measurements of fuel sprays. The same GtL diesel fuel as used in the first experiments was injected into the chamber at two different environmental conditions using a typical common rail diesel injector. For both conditions, one spray cone was measured using shadowgraphic imaging and Mie scattering, and the resulting images are compared with each other. As Mie scattering is selective of the liquid phase of the components, the shadowgraphic images show differences in the densities for the gas phases (second-order density gradients) and a combination of absorption and subtractive scattering of the back light, hence the shadow of the non-gaseous phase.

In both cases, the fuel was injected into the chamber at an injection pressure $p_{i n j}=80 \mathrm{MPa}$ and a fuel temperature $\mathrm{T}_{\mathrm{inj}}=323 \mathrm{~K}$. The images were taken at $1000 \mu \mathrm{s}$ after visible start of injection (vSOI). The first pair of images (Figure 11) shows the injection into subcritical conditions according to the critical properties of the fuel as estimated in the first series of experiments. In both single-shot images (shadowgraphic imaging on the left- and Mie scattering on the right-hand side), the typical shape of an injected diesel spray cone is visible. The penetration depths as well as the cone angle evaluated from both measurements are the same. The boundary between the spray and the surrounding area is clearly marked.

The second pair of images (Figure 12) shows injection into supercritical conditions. The penetration depth is far lower because of the higher conditions. In both images, the core of the spray ends in approximately the same position. An area of high density beyond and around the spray core is visible due to fluctuations of the refractive index on the left-hand image. This area is completely missing on the right-hand image. In the Mie image, the visible part of the spray is smaller at the tip. In contrast to the injection in subcritical conditions, the outline of the spray cone on the left-hand image is not as sharply defined. Rather, the parts of the spray away from the nozzle in particular 


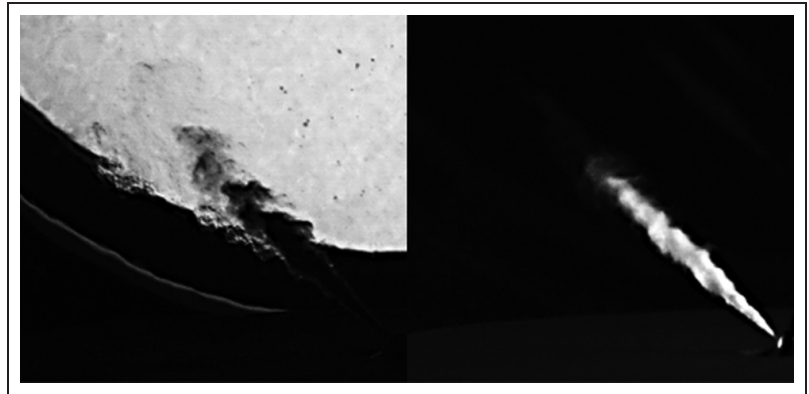

Figure I2. Injection of a GtL fuel ( $P_{i n j .}=80 \mathrm{MPa} ; \mathrm{T}_{\text {inj. }}=323 \mathrm{~K}$; $\left.t_{v s O I}=1000 \mu \mathrm{s}\right)$ into a supercritical environment $\left(\mathrm{P}_{\mathrm{g}}=8 \mathrm{MPa}\right.$; $\left.\mathrm{T}_{\mathrm{g}}=773 \mathrm{~K}\right)$.

become indistinct and no clear boundary between injected fluid and the surrounding gas is visible. While the phase boundary on the right-hand image is sharply defined, it becomes blurred in the left-hand image due to the density fluctuations of the high-density gas phase.

The visible parts of the spray cones are similar to the fluid injected into subcritical conditions when compared. As the Mie scattering technique represents only the liquid phase of the fluid, it can be seen that the injected fluid maintains a liquid phase only until it evaporates into the surrounding space. When surrounding conditions exceed the critical properties of the injected fluid, an area of high density around and especially at the end of the spray core becomes visible on the shadowgraphic image. It would not be possible to observe this area showing a higher density than a gaseous phase using Mie scattering. This indicates strongly that the area around the liquid core of the injected spray is a supercritical fluid.

Comparison of LIFIMie measurement of fuel sprays. Mie scattering and LIF were used to describe spray and evaporation behavior in engine-relevant conditions to investigate the same effect using measurement techniques based on different physical processes (Figures 13 and 14). For these experiments, a fluorescent fuel was needed since GtL diesel consists only of pure n-alkanes and has no significant absorption cross section in the near UV and visible spectra. ${ }^{29-31}$ Instead, the CEC RF06-03 reference fuel was used corresponding to EN $590 .{ }^{27}$ It contains a significant amount of aromatics that were excited by a third-harmonic Nd:YAG laser. The fluorescence signal was acquired with an intensified charge-coupled device (iCCD) camera.

For Mie scattering, flash lamps were used to illuminate the whole spray integrally as shown in a previous study. ${ }^{32}$ Since Mie scattering requires a phase boundary, the images show the presence of just the liquid phase in the ambient gas. Here, the spray cones have a penetration depth of $\sim 20 \mathrm{~mm}$ and are torpedo/cigar shaped.

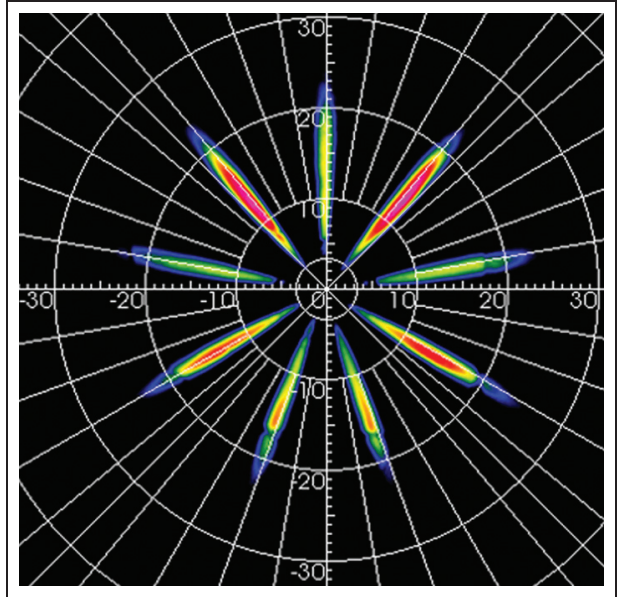

Figure 13. Spray image of a whole fuel spray $1000 \mu \mathrm{s}$ after vSOI (Mie) ( $\mathrm{PG}=7 \mathrm{MPa} ; \mathrm{T}_{\mathrm{G}}=900 \mathrm{~K} ; \mathrm{PF}_{\mathrm{F}}=140 \mathrm{MPa} ; \mathrm{T}_{\mathrm{F}}=298 \mathrm{~K}$; $\left.\mathrm{m}_{\text {inj. }}=50 \mathrm{mg}\right)$.

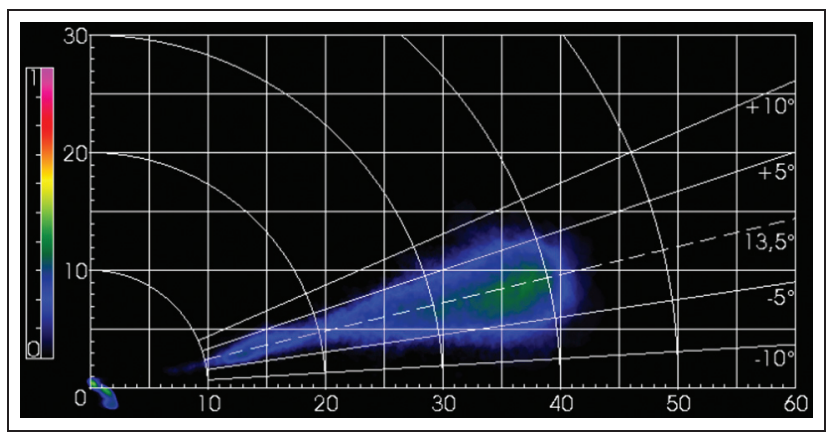

Figure I4. LIF image of a fuel cone $1000 \mu$ s after vSOI $\left(P_{G}=7 \mathrm{MPa} ; \mathrm{T}_{\mathrm{G}}=900 \mathrm{~K} ; \mathrm{PF}_{\mathrm{F}}=140 \mathrm{MPa} ; \mathrm{T}_{\mathrm{F}}=298 \mathrm{~K} ; \mathrm{m}_{\mathrm{inj}}=50 \mathrm{mg}\right)$.

The LIF technique sensitive to liquid and gaseous fuels gives a very different impression of fuel distribution. The fuel plume is conically shaped with a round tip. The intensity of the fluorescence signal is homogeneous over the whole plume, but slightly stronger in the regions far away from the nozzle. Nevertheless, no step in the intensity could be found in the region of maximum liquid fuel penetration, which would indicate a strong change in fuel density.

A comparison of the penetration depth of the liquid and the vapor phases ${ }^{25,32}$ shows that the penetration of the vapor phase is an extension of the propagation phase of the liquid fuel and represents a root of time dependency (Figure 15). This root of time dependency can be found at various operating points; the change in the ambient conditions or fuel pressure affects the function coefficients but not the type of function itself. ${ }^{32}$

A significant change in the density of the fuel caused by evaporation would affect the momentum exchange between the fuel phases and the ambient gas strongly and, therefore, the propagation velocity of the mixture. A loss of density would result in a strong deceleration. But, no kink is visible in the penetration depth curve, indicating that there is no significant change in density. 


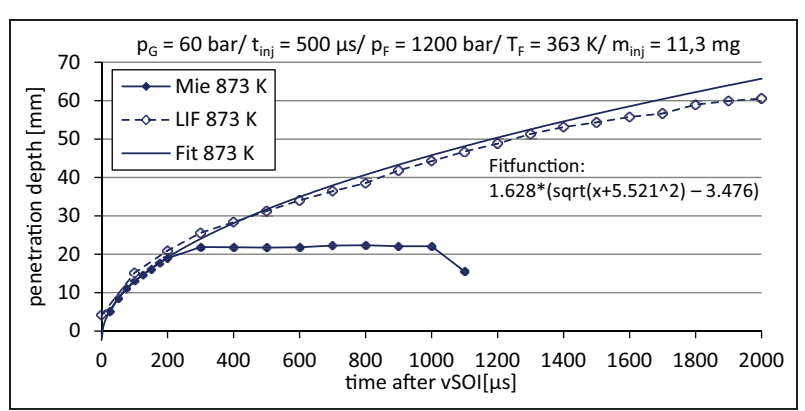

Figure 15. Comparison of the penetration depth of Mie and LIF measurements versus time.

\section{Discussion and conclusion}

The experiments indicate strongly that diesel fuel injected into conditions similar to those in modern diesel engines at higher loads exceeds its critical pressure and temperature and thus reaches a supercritical state without boiling. In the first experiments, a transition to a supercritical state was observed through disappearance of the phase boundary under steady state conditions. The influence of the surrounding atmosphere on the critical properties of the substance was found to be negligible. Although a GtL diesel fuel was transferred to a supercritical state in engine-relevant conditions, the exact temperature range of the transition was not determined as the thermocouples could not be positioned inside the fluid, and therefore, possible changes in the composition of the mixtures could not be monitored. The second series of experiments used different optical measurement techniques to examine the phase behavior of fuels injected into supercritical conditions in a transient injection process and at typical engine-relevant time scales. In particular, the Mie scattering measurement showed that detected areas of higher density than gases do not have to be liquid and thus gave a possible approach to differentiate between supercritical and liquid phases.

A comparison of the Mie scattering and LIF spray measurements showed no rapid change in the fuel concentration/density in the region of maximum liquid penetration. Furthermore, the intensity of the fluorescence signal is distributed homogeneously over the whole fuel cone and shows no higher concentration in the liquid region. Therefore, it can be assumed that the densities of the liquid fuel and the gasified fuel are similar. Our interpretation is that the fuel has transitioned to a supercritical state without density change. For sure, the study presented is qualitative and further research is necessary to show the effect more precisely, to qualify the experimental techniques for supercritical condition, and last but not least to quantify the condition at which the transition behavior changes and to quantify the effect on mixture formation.

Taking into account the work of other researchers introduced here, it can be concluded that the classical understanding of fuel injection (models applying fuel evaporation in all engine operating conditions) does not apply to the injection of a diesel fuel in modern enginerelevant conditions at higher loads - where cylinder pressures exceed the critical pressures of the diesel fuel components.

Although the phenomenon of supercritical injection is well known in liquid propellant rocket engines, little is known of the phase transition and mixing processes as well as heat and mass transfer, especially in the context of ICEs.

\section{Declaration of conflicting interests}

The author(s) declared no potential conflicts of interest with respect to the research, authorship, and/or publication of this article.

\section{Funding}

This research received financial support from the European Community and the Federal State of Bavaria for the project "Optical high pressure combustion bench test."

\section{References}

1. Lefebvre A. Atomization and sprays. New York: Taylor \& Francis, 1989.

2. Arai Y. Supercritical fluids. Berlin: Springer, 2002, p.446.

3. Clifford T. Fundamentals of supercritical fluids. New York: Oxford University Press, 1999.

4. Smith RM. Supercritical fluids in separation science - the dreams, the reality and the future. J Chromatogr A 1999; 856: 83-115.

5. Leipertz A. Technische Thermodynamik. Erlangen: Esytec Energie- und Systemtechnik GmbH, 2002, 448 pp.

6. Aschenbrenner O. Untersuchungen zu Phasengleichgewichten und Transportvorgängen gelöster Metallverbindungen in überkritischem Kohlendioxid. Karlsruhe: Chemieingenieurwesen und Verfahrenstechnik, Universität Karlsruhe, 2008.

7. Bellan J. Supercritical (and subcritical) fluid behavior and modeling: drops, streams, shear and mixing layers, jets and sprays. Pasadena, CA: Jet Propulsion Laboratory, California Institute of Technology, 1999.

8. Chehroudi B. Recent experimental efforts on highpressure supercritical injection for liquid rockets and their implications. Int J Aerosp Eng 2012; 2012: 121802 (31 pp).

9. Chehroudi B, Talley D, Mayer W, Branam R, Smith JJ and Schik A. Understanding injection into high pressure supercritical environments. In: 5th international conference on liquid rocket propellant, Chattanooga, TN, 27-30 October 2003.

10. Sonderforschungsbereich Transregio 75: Tropfendynamische Prozesse unter extremen Umgebungsbedingungen, http://www.sfbtrr75.de/

11. Weckenmann F, Bork B, Oldenhof E, Lamanna G, Weigand B and Böhm B. Single acetone droplets at supercritical pressure: droplet generation and characterization of PLIFP. Z Phys Chem 2011; 225: 1417-1431.

12. Weckenmann F. Experimental investigation of droplet evaporation under extreme conditions, 2012, http:// 
www.simtech.uni-stuttgart.de/lehre/graduiertenschule/ Milestone/MSR/Report_Weckenmann.pdf

13. Dahms RN, Manin J, Pickett LM and Oefelein JC. Understanding high-pressure gas-liquid interface phenomena in Diesel engines. $P$ Combust Inst 2013; 34: $1667-1675$.

14. Oefelein JC, Dahms RN and Lacaze G. Detailed modeling and simulation of high-pressure fuel injection processes in diesel engines. SAE Int J Engine 2012; 5: 1410 1419.

15. Oefelein JC, Dahms RN, Lacaze G, Manin JL and Pickett LM. Effects of pressure on the fundamental physics of fuel injection in diesel engines. In: 12th international conference on liquid atomization and spray systems (ICLASS 2012), Heidelberg, 2-6 September 2012.

16. Zhu GS and Aggarwal SK. Fuel droplet evaporation in a supercritical environment. J Eng Gas Turbine Power 2002; 124: 762-770.

17. Ghassemi H, Baek SW and Khan QS. Experimental study on binary droplet evaporation at elevated pressures and temperatures. Combust Sci Technol 2006; 178: 10311053.

18. Anitescu G, Bruno TJ and Tavlarides LL. Dieseline for supercritical injection and combustion in compressionignition engines: volatility, phase transitions, spray/jet structure, and thermal stability. Energ Fuel 2012; 26: 6247-6258.

19. Peng D-Y and Robinson DB. A new two-constant equation of state. Ind Eng Chem Fund 1976; 15: 59-64.

20. Giorgio S. Equilibrium constants from a modified Redlich-Kwong equation of state. Chem Eng Sci 1972; 27: 1197-1203.
21. Lee BI and Kesler MG. A generalized thermodynamic correlation based on three-parameter corresponding states. AIChE J 1975; 21: 510-527.

22. VDI. VDI-Wärmeatlas. Berlin: Springer-Verlag, 2013.

23. AspenTech. Aspen Plus 12.1. Cambridge, 2003.

24. Konynenburg PHV and Scott RL. Critical lines and phase equilibria in binary van der Waals mixtures. Philos T R Soc S A 1980; 298: 495-540.

25. Vogel T, Lutz M, Wensing M and Leipertz A. Influence of fuel mixture on spray formation in diesel processes. In: Europe 2010, 23rd annual conference on liquid atomization and spray systems (ILASS), Brno, 6-8 September 2010.

26. Vogel T, Lutz M, Iannuzzi S, Wensing M and Leipertz A. Influence of the fuel quantity on the spray formation and ignition under current engine relevant conditions. SAE technical paper 2011-01-1928, 2011.

27. EN590: Automotive fuels - diesel: requirements and test methods, 2009.

28. Lin R and Tavlarides LL. Thermal stability and decomposition of diesel fuel under subcritical and supercritical conditions. J Supercrit Fluid 2013; 75: 101-111.

29. Hirayama F and Lipsky S. Fluorescence of saturated hydrocarbons. J Chem Phys 1969; 51: 3616-3617.

30. Hirayama F, Rothman W and Lipsky S. Fluorescence of saturated hydrocarbons - II. The effect of alkyl substituents. Chem Phys Lett 1970; 5: 296-298.

31. Rothman W, Hirayama F and Lipsky S. Fluorescence of saturated hydrocarbons - III. Effect of molecular structure. J Chem Phys 1973; 58: 1300-1317.

32. Vogel T, Rieß S, Lutz M, Wensing $M$ and Leipertz A. Comparison of current spray models under high pressure and high temperature engine relevant conditions. In: Europe 2011, 24th annual conference on liquid atomization and spray systems (ILASS), Estoril, 5-7 September 2011. 